\title{
Total vaginal hysterectomy: outcome analysis of 108 cases at a tertiary centre
}

\section{Monika Ramola*, Divya Goswami, Vineeta Gupta, Nidhi Kumari, Priyanka Chaudhari}

Department of Obstetrics and Gynecology, SGRRIMHS, Dehradun, Uttarakhand, India

Received: 04 October 2016

Accepted: 08 October 2016

\section{*Correspondence:}

Dr. Monika Ramola

E-mail: dr.monika.ms@gmail.com

Copyright: (C) the author(s), publisher and licensee Medip Academy. This is an open-access article distributed under the terms of the Creative Commons Attribution Non-Commercial License, which permits unrestricted non-commercial use, distribution, and reproduction in any medium, provided the original work is properly cited.

\begin{abstract}
Background: The aim of this study is to evaluate, analyze the indications of surgery, patients profile with respect to age group, parity, and comorbidities, intraoperative techniques, intra and post-operative complications and postoperative recovery.

Methods: A hospital based cross sectional descriptive study of 108 cases was conducted in the department of Obstetrics and Gynecology in a tertiary hospital over a period of one year. All patients admitted with benign gynecological conditions of the uterus were included in study. The patients with uterine prolapse, uterine size $>16 \mathrm{wks}$ and more than one previous sections were excluded from the study.

Results: Among all the indications of TVH, abnormal uterine bleeding was the most common. Mean age group was 44.89 years and the mean parity was 2. Majority of the patients had no intra and post-operative complications. Postoperative recovery was good with shorter hospital stay.

Conclusions: TVH should be promoted as the route of choice for all benign gynaecological conditions. It is safe to do TVH in patients who are at poor general anaesthesia risk. In a state like Uttarakhand where medical facilities are hard to avail due to difficult geographic terrain, $\mathrm{TVH}$ has a special role .In lack of endoscopic facility, trained medical and paramedical staff and lack of postoperative monitoring instead of; there is a need to promote TVH. To top it all, TVH is the most cost effective route of hysterectomy. It is truly the natural orifice scarless surgery.
\end{abstract}

Keywords: Total vaginal hysterectomy (TVH), Hysterectomy, Debulking

\section{INTRODUCTION}

Hysterectomy can be done by many routes such as abdominal, vaginal, laparoscopic and robotic assisted surgery. Conrad Langenbeck in 1813 performed the first total modern vaginal hysterectomy. ${ }^{1}$ Robert Kovac in 1970 showed that more than $80 \%$ of the hysterectomies could be done safely as TVH. ${ }^{2}$ Yet, even today, $2 / 3^{\text {rd }}$ of the hysterectomies are still done by abdominal route. Of the rest, about half are done vaginally and half are done endoscopically. ${ }^{3}$ There is no absolute contraindication to vaginal hysterectomy. ${ }^{4}$ Victor Bonney in 1918 truly said that the more one performs vaginal hysterectomies, the less contraindication one encounters. LAVH enjoyed its place in last decade, when it became fashionable to perform a hysterectomy with a technically superior laparoscope. Many gynaecologists condemn LAVH as a dangerous and unnecessary operation that is substituted for vaginal hysterectomy.

Abdominal route is inferior to both vaginal and laparoscopic route in terms of patient recovery and satisfaction. Vaginal approach for hysterectomy is desirable in our state since the health resources are limited. TVH is performed in selected centres, majority of the clinicians not offering it routinely. Uncertainty about its feasibility and safety accounts for the reluctance by many to offer it. 
Thus, research data confirming the safety and feasibility of this procedure in local setting would be helpful to both the clinician and the patients to consider a natural orifice approach for hysterectomy. Therefore, we undertook this study in a tertiary care hospital in Uttarakhand which caters to the remotest area of the hilly terrain.

\section{METHODS}

The patients admitted for hysterectomy with benign gynaecological conditions excluding uterine prolapse who underwent TVH from July 2015 to July 2016 were included in the study. Patients who needed additional surgery like adenexectomy were also included in the study. Patients with history of more than 1 previous section, uterine size $>16$ weeks, and adenexal pathology were excluded from the study. These patients were subjected to thorough physical and general examination. All necessary preoperative investigations were carried out. The age, parity, body mass index and indication of surgery were noted .Patients was assessed under regional aneasthesia either spinal or epidural for the mobility of the uterus and accessibility of uterosacrals from the vaginal route.

The operative technique was circumferential incision around cervix, followed by cutting of pubovesicocervical ligament and mobilization of urinary bladder. The anterior and posterior pouches were opened. Uterosacrals and cardinal ligament were clamped, cut and transfixed followed by cutting and ligation of uterine vessels. Bigger sized uteri needed debulking techniques like bisection, coring, enucleation and myomectomy. This was followed by clamping of bilateral fundal structures and delivery of the uterus. Vaginal drain and foley's catheter was put.

The operative time, blood loss and intraoperative complications were noted in each case. In the postoperative period data was analyzed with respect to any complications and fit for discharge period.

\section{RESULTS}

Overall 108 women with benign gynaecological diseases admitted between July 2015 to July 2016 who underwent TVH were analyzed. The mean age of the patients was 44.89 years. Majority of the patients were in the age group of $41-45$ years $(36.1 \%)$ (Table 1$)$.

Table 1: Age distribution.

\begin{tabular}{|ll|}
\hline Age (yrs) & $\mathbf{N}(\%)$ \\
\hline$<35$ & $2(1.9)$ \\
\hline $36-40$ & $22(20.4)$ \\
\hline $41-45$ & $39(36.1)$ \\
\hline $46-50$ & $29(26.9)$ \\
\hline$>50$ & $16(14.8)$ \\
\hline
\end{tabular}

Body mass index of 83 patients $(76.9 \%)$ was in the range of $26-30 \mathrm{~kg} / \mathrm{m}^{2}$. About fifteen patents $(13.9 \%)$ who were obese also successfully underwent TVH (Table 2).

Table 2: Body mass index.

\begin{tabular}{|ll|}
\hline BMI & N $(\%)$ \\
\hline$<25$ & $10(9.3)$ \\
\hline $26-30$ & $83(76.9)$ \\
\hline $31-35$ & $12(11.1)$ \\
\hline$>35$ & $3(2.8)$ \\
\hline
\end{tabular}

$42(38.9 \%)$ women were of parity 2 . It was possible to perform TVH in $3(2.8 \%)$ nullipara women as depicted in Table 3.

Table 3: Parity.

\begin{tabular}{|ll|}
\hline Parity & $\mathrm{N}(\%)$ \\
\hline Nullipara & $3(2.8)$ \\
\hline $\mathrm{P}_{1}$ & $13(12)$ \\
\hline $\mathrm{P}_{2}$ & $42(38.9)$ \\
\hline $\mathrm{P}_{3}$ & $28(25.9)$ \\
\hline $\mathrm{P}_{4}$ or more & $22(20.4)$ \\
\hline
\end{tabular}

The most common indication for TVH was abnormal uterine bleeding in $43.5 \%$ followed by fibroid uterus in $27.8 \%$, adenomyosis in $12 \%$, PID in $8.3 \%$, postmenopausal bleeding in $5.6 \%$ and cervical dysplasia in $2.8 \%$ patients as shown in Table 4 .

Table 4: Indication of surgery.

\begin{tabular}{|ll|}
\hline Indication of surgery & N $(\%)$ \\
\hline PID & $9(8.3)$ \\
\hline AUB & $47(43.5)$ \\
\hline Fibroid & $30(27.8)$ \\
\hline Adenomyosis & $13(12.0)$ \\
\hline Postmenopausal bleeding & $6(5.6)$ \\
\hline Cervical dysplasia & $3(2.8)$ \\
\hline
\end{tabular}

Table 5: Size of uterus.

\begin{tabular}{|ll|}
\hline Size of uterus (wks) & $\mathbf{N}(\%)$ \\
\hline $8-10$ & $40(37)$ \\
\hline $10-12$ & $44(40.7)$ \\
\hline $12-14$ & $10(9.3)$ \\
\hline $14-16$ & $14(13)$ \\
\hline
\end{tabular}

Size of the uterus was in the range of 8-10 weeks in 40 patients and 10-12 weeks in 44 patients (Table 5). 14 patients had sizes more than 14 weeks. Bilateral salpingoopherectomy was done in 8 patients $(7.4 \%) .7$ $(6.5 \%)$ patients had history previous of one cesarean section. $89.8 \%$ patients under went operation in spinal aneasthesia. Only $10.2 \%$ patients needed epidural aneasthesia. 
Mean duration of surgery was $92.03 \mathrm{~min}$ as shown in Table 6. The mean blood loss was $87.04 \mathrm{ml}$ as shown in Table 7. $60 \quad(54.6 \%)$ patients needed debulking techniques like bisection in $37(34.3 \%)$ patients and enucleation in $14(13 \%)$ patients as depicted in Table 8.

Table 6: Duration of surgery.

\begin{tabular}{|ll|}
\hline Duration of surgery (min.) & N $(\%)$ \\
\hline$<90$ & $73(67.6)$ \\
\hline$>90$ & $35(32.5)$ \\
\hline
\end{tabular}

Mean duration of surgery $=92.03 \mathrm{~min} ; \mathrm{SD}=15.687$

Table 7: Blood loss.

\begin{tabular}{|ll|}
\hline Blood loss $(\mathrm{ml})$ & $\mathbf{N}(\%)$ \\
\hline $50-100$ & $87(80.6)$ \\
\hline $100-150$ & $19(17.6)$ \\
\hline$>150$ & $2(1.9)$ \\
\hline
\end{tabular}

Mean blood loss $=87.04 \mathrm{ml} ; \mathrm{SD}=24.836$

Table 8: Debulking techniques.

\begin{tabular}{|ll|}
\hline Debulking techniques & $\mathbf{N}(\%)$ \\
\hline Coring & $6(5.6)$ \\
\hline Bisection & $37(34.3)$ \\
\hline Enucleation & $14(13.0)$ \\
\hline Myomectomy & $2(1.9)$ \\
\hline Coring+Myomectomy & $1(0.9)$ \\
\hline None & $48(44.4)$ \\
\hline
\end{tabular}

Table 9: Intra and post-operative complications.

\begin{tabular}{|ll|}
\hline Complications & $\mathbf{N}(\%)$ \\
\hline Bladder injury & $3(2.8)$ \\
\hline Bowel injury & $1(0.9)$ \\
\hline Febrile morbidity & $8(7.4)$ \\
\hline Blood transfusion & $6(5.6)$ \\
\hline UTI & $7(6.5)$ \\
\hline None & $83(76.9)$ \\
\hline
\end{tabular}

Table 10: Fit for discharge period.

\begin{tabular}{|ll|}
\hline Fit for discharge (hrs) & $\mathbf{N}(\%)$ \\
\hline $48-72$ hrs & $42(38.9)$ \\
\hline $72-96$ & $48(44.4)$ \\
\hline$>96$ & $18(16.7)$ \\
\hline
\end{tabular}

The intra operative complications were bladder injury in three $(2.8 \%)$ and bowel injury in one $(0.9 \%)$ patient which were promptly identified and repaired during primary surgery. Post-operative complications like febrile morbidity and UTI was reported in $8(7.4 \%)$ and $7(6.5 \%)$ patients respectively. Six patients $(5.6 \%)$ required blood transfusion either in per op and post op period as illustrated in Table 9. Most of the patients (83.3\%) were fit for discharge by 3-4 days as shown in Table 10. Thus, we have noted less morbidity and no mortality in our study.

\section{DISCUSSION}

This observational study shows that TVH is a safe and feasible route in our hospital setting. It is a good option even for cases with enlarged uteri and the need for adenexectomy. The usual contraindications for TVH are lack of descencus, nulliparity, no previous vaginal delivery, large uterus, obliterated posterior cul de sac, endometriosis, need for adenexectomy, obesity and prior cesarean deliveries or abdominal surgeries. Many studies refute these contraindications with successful TVH being done in patients with above said complications. ${ }^{6-11}$

About 108 patients underwent successful TVH in our centre. The mean age of the patients was 44.89 years and majority of the patients i.e. 39 patients were in the age group of 41-45 years. This is similar to study conducted by Bharatnur and Kumari $\mathrm{S}$ et al. ${ }^{12,13}$

$42(38.9 \%)$ patients had parity 2 which is comparable to study by Patel et al. ${ }^{14}$ Agostini et al successfully operated on $50(96.2 \%)$ nulliparous women. In our study, we performed successful TVH in $3(2.8 \%)$ nulliparous women. ${ }^{6}$

Obesity is no more a contraindication to TVH. IsikAkbay et al operated on $180(48.8 \%)$ obese patients. ${ }^{11} \mathrm{We}$ had $15(13.9 \%)$ obese patients who had BMI more than $30 \mathrm{~kg} / \mathrm{m}^{2}$. Kumar $\mathrm{N}$ et al operated on 11 patients who had previous one cesarean section. ${ }^{15}$ In our study, 7 (6.5\%) patients had previous one cesarean section.

The most common indication of surgery was abnormal uterine bleeding which is similar to study by Patel et al. ${ }^{14}$ $84(13.9 \%)$ patients had sizes of the uterus below 12 weeks which matched the study conducted by Chaminda et al in Srilanka. ${ }^{16}$

Debulking techniques was used by different authors in different studies. In our study debulking technique was used in $55.6 \%$ of patients. Bisection $(34.3 \%)$ was the most common technique employed by us. Davies et al and Mazdisnian et al resorted to these techniques. ${ }^{10,17}$ Kumar and Antony successfully carried out vaginal hysterectomies in $95 \%$ patients and $75 \%$ of their patients needed morcellation or hemisection or myomectomy. ${ }^{18}$

Mean operating time was 92.03 min which is comparable to Magos A et al and Kovac et al which showed 84.3 and 94 minutes respectively. ${ }^{19,2}$

Mean blood loss was $87.04 \mathrm{ml}$ in our study. Blood loss ranged from $30 \mathrm{ml}-160 \mathrm{ml}$ in different studies. ${ }^{13,20}$

Visceral injuries like bladder and bowel injuries were reported differently in different studies. Kumari S et al noted bladder injury in $0.78 \%$ patients whereas Shanthini et al noted bladder injury in one $(1.9 \%)$ patient. ${ }^{13,20} \mathrm{We}$ noted bladder injury in three $(2.8 \%)$ patients and bowel 
injury in one $(0.9 \%)$ patient which were recognized and promptly repaired during primary surgery.

Postoperative complications were minimal which included febrile morbidity and UTI in $7.4 \%$ and $6.5 \%$ respectively which were tackled successfully. Six patients $(5.6 \%)$ received blood transfusion either in intraoperative or post-operative patients. The rate of blood transfusion in study conducted by Chaminda et al was $1.9 \%$. We reported more blood loss as baseline hemoglobin was low in our patients.

The mean fit for discharge period was 3-4 days which is similar to as reported by Dorsey et al. ${ }^{21}$

\section{CONCLUSION}

The present study was undertaken to evaluate the safety of TVH in patients with non descent uteri with benign gynaecological conditions. We concluded that TVH is a safe and effective route of hysterectomy. Therefore, TVH should be promoted as the route of choice for benign gynaecological conditions with proper case selection.

\section{Funding: No funding sources}

Conflict of interest: None declared

Ethical approval: The study was approved by the Institutional Ethics Committee

\section{REFERENCES}

1. Nieboer TE ,Johnson N, Barlow D, Lethaby A, Tavender E. Surgical approach to hysterectomy for benign gynaecological disease. Cochrane Database of Systemic Reviews. 2006;2:CD003677.

2. Kovac SR. Guidelines to determine the route of hysterectomy. Obstet Gynaecol. 1995;85:18-23.

3. Wu JM, Wetcher ME, Geller EJ, Nguyen TV, Visco AG. Hysterectomy rates in the United States, 2003. Obstet Gynaecol. 2007;110(5):1091-95.

4. Martin X, Giata A, Golfier F, Raudrant D. Hysterectomy for a benign lesion: can the vaginal route be used in all cases? Journal Gynecol Obstet Biol Repord. 1999;28:124-30.

5. Maresh MJ, Metcalfe MA, Mc Pherson K, Overton C, Hall V, Hargreaves J, et al. The Value national hysterectomy study: description of the patients and their surgery. $\mathrm{Br}$ J Obstet Gynaecol. 2002;109(3):302-12.

6. Agostini A, Bretelle F, Cravello L. Vaginal hysterectomy in nulliparous women without prolapse; a prospective comparative study. BJOG 2003;110(5):515-18.

7. Varma R, Tahseen S, Lo Kugamage AU, Kunde D. Vaginal route as the norm when planning hysterectomy for benign conditions; change in practice. Obstet Gynaecol 2001;97(4):613-6 .
8. Sheth SS, Malpani AN. Vaginal hysterectomy following previous cesarean section. Int J Gynaecol Obstet. 1995;50(2):165-69.

9. Sizzi O, Paprella P, Bonito C. Laparoscopic assistance after vaginal hysterectomy and unsuccessful access to the ovaries or failed uterine mobilization: changing trends. JSLS. 2004;8(4):33946.

10. Davies A, O`Connor H, Magos AL. A prospective study to evaluate oophorectomy at the time of vaginal hysterectomy. $\mathrm{Br} \mathrm{J}$ Obstet Gynaecol 1996;103(9):915-20.

11. Isik-Akbay EF, Harmanli OH, Panganamamula UR. Hysterectomy in obese women: A comparison of abdominal and vaginal routes. Obstet Gynaecol 2004;104 (4):710-14.

12. Bharatnur S. Comparative study of abdominal versus vaginal hysterectomy in non-descent cases. The Internet Journal of Obstetrics and Gynaecology. 2011;15(2):1528-8439.

13. Kumari S, Biswas A. Non descent vaginal hysterectomy: An experience of 508 cases. Global Journal for Research Analysis. 2016;5(3):142-44.

14. Patel A, Pawani C. Non descent Vaginal Hysterectomy; Safety and Feasibility. International Journal of Scientific Research. 2015;4(9):613-15.

15. Kumar N, Tayade S. Int J Reprod Contracept Obstet Gynaecol. 2015;4(3):785-89.

16. Chaminda SH. Outcome of Non-Descent Vaginal Hysterectomy at a Single Centre in Sri Lanka: an observational study .Sri Lanka Journal of Obstetrics and Gynaecology. 2016;37(3):42-6.

17. Mazdisnian F, Kurzel RB, Coe S. Vaginal hysterectomy by uterine morcellation: an efficient, nonmorbid procedure. Obstet Gynaecol. 1995;86:604.

18. Kumar S, Antony ZK. Vaginal hysterectomy for benign nonprolapse uterus-initial experiences. J Obstet Gynaecol Ind. 2004;54:60-3.

19. Magos A, Boyiras N, Sinha R. Vaginal hysterectomy for large uterus. $\mathrm{Br} \mathrm{J}$ Obstet Gynaecol. 1996;103:246-51.

20. Shanthini NF, Poomalar GK, Jayasree M, Bupathy A. Evaluation of complications of abdominal and vaginal hysterectomy. Int J Reprod Contraception Obstet Gynaecol. 2012;1(1):7-11.

21. Dorsey JH, Steinberg EP, Holtz PM. Clinical indications for hysterectomy route; patient characteristics or physician reference? Am J Obstet Gynaecol. 1995;173(5):1452-60.

Cite this article as: Ramola M, Goswami D, Gupta V, Kumari N, Chaudhari P. Total vaginal hysterectomy: outcome analysis of 108 cases at a tertiary centre. Int J Reprod Contracept Obstet Gynecol 2016;5:3679-82. 